\title{
EL HOGAR: AMIGO O ENEMIGO EN TIEMPOS DE PANDEMIA
}

Home: Friend or Enemy in Times of the Pandemic

Jorge Luis Montero Rodríguez, Universidad de Guadalajara

Correo electrónico: jorgelmontero86@gmail.com

Fecha de envío: 2020/08/08

Fecha de aceptación: 2020/11/10

Resumen. La pandemia actual por Covid-19 ha puesto en evidencia la vulnerabilidad humana ante el confinamiento doméstico que ha deparado en afecciones físicas y psíquicas. La hipótesis es que el hogar ha sido convertido en un recinto donde ahogar los desafueros en un mundo contemporáneo donde la ciudad es el principal escenario del sobrerrendimiento y la autoexplotación del ser humano. La casa se ha convertido en un objeto de producción y consumo, un signo del desvanecimiento del hogar. La persona rendida al trabajo y a la positividad de la vida social la asume como receptáculo y cubículo para consumir y acaparar, no como un hogar. Hoy, cuando más necesitamos de la amabilidad hogareña, los síntomas psíquicos y emocionales muestran lo contrario. El hogar debe ser rescatado.

Palabras claves: casa citadina, ciudad, familia, hogar, ser humano, trabajo.

\begin{abstract}
The current Covid-19 pandemic shows the human vulnerability to the domestic confinement that has provoked some physical and mental illness. The hypothesis is that home has been transformed in an enclosure where to drown the outrages inside a contemporary world where city is the main scene of over-achievement and self-exploitation of human being. The house has become an object of production and consumption, a sign of the home's fading. Human being, subdued to job and the social life's positivity, assumes the house as receptacle and cubicle for consuming and hoarding, not as a home. Today, when we need most the kindness of home, some psychic and emotional symptoms show the opposite. Home must be rescued.
\end{abstract}

Keywords: City, city house, family, home, human being, employ. 


\section{Introducción}

Hoy, los habitantes del mundo se enfrentan a un civilizatorio debate entre sus vidas y los peligros que hay 'afuera'. Un microscópico virus —el SARS-CoV2 - ha dejado en entredicho la ilusoria seguridad que la humanidad le había adjudicado a la ciencia y al progreso tecnológico. En la actualidad, las grandes ciudades, las urbes globales y las zonas metropolitanas desarrolladas tecnológicamente no son el espacio de vida cotidiana; la casa ha vuelto a ser ese recinto del recogimiento y resguardo que siempre fue. Pero ese refugio se ha convertido en la prisión de muchos. ${ }^{1}$ ¿Por qué sucedo esto? ¿Cómo ha sido posible que el hogar se haya convertido en el calvario de los desesperados? ¿Es este un problema que debe ser atendido por la psicología, la arquitectura o por la filosofía? La tesis del presente artículo plantea que el hogar ha sido desvanecido en la mera casa donde ahogar los desafueros intensificados en la vida diaria, por lo que, en tiempos de confinamiento domiciliar en defensa de la vida, la casa se vuelve extraña e intolerable.

Los argumentos que sustentan dicha tesis radican en el rendimiento laboral entendiendo al trabajo contemporáneo como empleo remunerado multivariado-, la promiscuidad de lo positivo y el copiado de los estilos de vida ingénitos de la moda capitalista. Las oportunidades para la contemplación, la meditación y el descanso dentro del medio hogareño han sido aprovechadas por las persuasiones y los incentivos capitales para mantener en marcha a la maquinaria. Por consecuencia, el hogar va desapareciendo a través de una figura dominante de casa citadina que muta su significado, se objetiva para un mercado de capitales y pierde su ser trascendente vulnerabilizando la vida humana.

\section{Del hogar cálido hacia la fría casa}

En la modernización del vivir humano surgió un tipo de casa que representó el signo físico, estático y continuo del estilo de vida capitalista obrero; su modificación fue tanto formal y

\footnotetext{
${ }^{1}$ Samantha K. Brooks et al., "The Psychological Impact of Quarantine and How to Reduce it: Rapid Review of the Evidence", The Lancet 395, núm. 10227 (marzo, 2020), 913-916. https://doi.org/10.1016/S01406736(20)30460-8; Associated Press, "Cuando quédate en casa suena a prisión domiciliaria", 20 minutos, 6 de marzo, 2020. https://www.20minutos.com/noticia/273972/0/cuando-quedate-en-casa-suena-a-prisiondomiciliaria/.
} 
estética como sustancial. Un nuevo espíritu del hogar fue implantado en las vidas privadas de la capitalista sociedad puritana que encontró la moral citadina en una ética del trabajo arduo y glorificante. ${ }^{2}$ La vivienda fue vivida en las horas posteriores a las jornadas laborales; de siete días a la semana, pasaron a ser horas alternas y el domingo santo. La casa fue aceptada como el lugar a dónde regresar al final del día, la estabilidad familiar para los padres y, como dijo Bachelard, el hogar originario en la vida de los infantes. ${ }^{3}$

Luego, en la posguerra, el movimiento arquitectónico racional, estéticamente austero y funcional entregó a los ciudadanos nuevas formas de casas dotadas del espíritu del progreso y el desarrollo. A la par, las fábricas seriaron sus procesos de producción y más obreros trabajaron en ellas por más horas diarias. Cuando llegaban las crisis económicas a los diversos países, tener dos o más empleos fue la norma para la subsistencia. La vida transcurría más tiempo en los puestos de trabajo y las ciudades que dentro de las casas.

Hoy, incluso asistimos a una intromisión mayor del trabajo dentro de la casa. Ya no únicamente los trabajos domésticos que en la contemporaneidad capitalista y patriarcal son demeritados legal y económicamente para las mujeres que los realizan, ${ }^{4}$ sino también el teletrabajo que toma fuerza en tiempos de aislamiento domiciliar; causante del aumento de la jornada laboral y del estrés en una hiperconectividad que transfigura el reposo hogareño. ${ }^{5}$ Por ejemplo, el 42 por ciento de los trabajadores estadounidenses trabajan tiempo completo en casa; son casi el doble de los que trabajan fuera del hogar. ${ }^{6}$

La realidad del trabajo actual es problémica socialmente, pues manifiesta la soledad del trabajador descolectivizado y globalizado que individualmente es reubicado en un

\footnotetext{
${ }^{2}$ Max Weber, La ética protestante y el espíritu del capitalismo, trad. de Luis Legaz (México: Fondo de Cultura Económica, 2012), 85-114.

${ }^{3}$ Gastón Bachelard, La poética del espacio, trad. de Ernestina de Champourcin (Buenos Aires: Fondo de Cultura Económica, 2000), 36.

${ }^{4}$ María E. Valenzuela y Claudia Mora, (eds.), Trabajo doméstico: un largo camino hacia el trabajo decente (Santiago de Chile: Organización Internacional del Trabajo, 2009), 9-304.

${ }^{5}$ Verónica De Vita, "El teletrabajo ha generado más estrés y también ha obligado a ampliar el horario laboral", Los Andes, 19 de abril, 2020. https://www.losandes.com.ar/article/view/?slug=el-teletrabajo-hagenerado-mas-estres-y-tambien-ha-obligado-a-ampliar-el-horario-laboral; Catalina Gallo, "Estudios muestran que la pandemia y el confinamiento han afectado la salud mental de la población", France 24, 11 de septiembre, 2020. https://www.france24.com/es/20200911-impacto-pandemia-salud-mental.

${ }^{6}$ Nicholas Bloom, "How Working from Home Works Out", Stanford Institute for Economic Policy Research, junio, 2020. https://siepr.stanford.edu/research/publications/how-working-home-works-out\#anchor-1.
} 
sistema productivo organizacional que responde al trabajo fluido e intensificado. ${ }^{7}$ Hoy se trabaja en cualquier tiempo y con duraciones a veces excesivamente prolongadas, y se trabaja en cualquier espacio despojado de topofilia y reconfigurado como un objeto del empleo. ${ }^{8}$ Ésta es una característica ontológica del empleo contemporáneo que se reafirma como liberal y maleable para sociedades y culturas diversas, pero globalizadas.

Actualmente, las políticas de flexibilización laboral y de apertura del mercado laboral por una globalización que desconfigura las dinámicas particulares de los pueblos, ponen en mano de las personas modalidades de trabajo tan variadas como explotadoras, a saber: el subempleo, el outsourcing, el freelance, el emprendedurismo, el teletrabajo y otros trabajos no clásicos. ${ }^{9}$ Esto demuestra cómo el sentido ontológico del trabajo ha sido transformado progresivamente por los poderes capitalistas, desde el mecanicismo moderno del trabajo asalariado como fuerza, mercancía y deber social, hasta el actual empleo espoliativo de la efectividad, la especialización y el rendimiento superlativos y autorreferenciados a las personas laborantes en todo espacio y tiempo. ${ }^{10}$ En consecuencia, se podría aceptar actualmente que el empleo formal-urbano remunerado está en crisis. ${ }^{11}$

Ya sea en regímenes laborales típicos o en empleos atípicos y flexibles, dichos espolios mantienen a las personas en una constante reposición de ellos. ${ }^{12}$ Entiéndase que a pesar de que las modalidades de empleos adopten un trabajo eventual, estacional, por plazos, de prestación discontinua, subcontrataciones, o a domicilio, la relación de dependencia al empleo no desaparece. En especial quien trabaja a domicilio está dependiente a otros agentes intermediarios, y excluido del mercado del producto. ${ }^{13}$

Una vez más, la esfera laboral permea y trastoca dominantemente la esfera social y la doméstica. Es por esto que hoy, con el incremento de las necesidades, el deseo generalizado de las sociedades por adscribirse a estilos de vida consumistas y la feroz

\footnotetext{
7 Juan José Castillo, "La soledad del trabajador globalizado", Revista Papeles, núm. 108 (invierno, 2009), 11-18. https://www.fuhem.es/wp-content/uploads/2018/12/la_soledad_del_trabajador_globalizado_J.J.CASTILLO.pdf. 8 Jorge Luis Montero, "Trabajador y espacio del trabajo contemporáneo. Crítica ontológica al empleo". Sincronía 24, no. 78 (julio-diciembre, 2020), 156, DOI:10.32870/sincronia.axxiv.n78.

${ }^{9}$ Enrique de la Garza (coord.), Trabajo no clásico, organización y acción colectiva (México: Universidad Autónoma Metropolitana / Plaza y Valdés, 2011), 9-329.

${ }^{10}$ Ibid., 165.

${ }^{11}$ Pablo Guerra, Sociología del trabajo (Montevideo: Kolping, 2011), 11.

${ }^{12}$ Montero, "Trabajador y espacio", 165.

${ }^{13}$ Guerra, Sociología del trabajo, 329-334.
} 
competencia en el mercado laboral, las varias modalidades de empleos, especialmente el teletrabajo, impactan negativamente en la fenomenología del hogar.

Tristemente, hoy la casa parece haber perdido ese fuego del hogar que daba sentido a la humanidad calma de lo íntimo y por ello, en los actuales tiempos de pandemia y confinamiento domiciliario, los síntomas antidomiciliares son exteriorizados. Por eso, la reflexión filosófica resulta apremiante.

\section{Desmontando la casa para problematizar al hogar}

¿Es la casa citadina de hoy un hogar? Y, también se pregunta por las conductas y comportamientos humanos que dotan de significado al lugar de residencia. Cuando las personas laborales y urbanas, luego de casi un día entero viviendo en la ciudad, regresan a sus casas, se despojan de sus cansancios, insatisfacciones, fracasos y desalientos que rondan los reclamos a la vida, los autorreproches y las consolaciones. Cuando esto sucede, la casa pasa a ser un recinto donde ahogar los desafueros y, por ende, parece perder su carácter y valor como hogar inigualable. Se podría suponer que la casa ha mutado en un recinto anegado por el exceso, las ambiciones, los reclamos, las penurias y las autovejaciones donde es difícil moverse con amabilidad. Esto se ha convertido en un tormento para las personas que hoy están en confinamiento domiciliario y no saben qué hacer con todo ese tiempo perdido dentro de sus habitáculos.

En tiempos anteriores, la dinámica cotidiana era otra. La gente caminaba apresurada hacia los puestos de trabajo, transitaba rauda dentro de los automóviles privados y los vehículos públicos hacia los centros comerciales, clubes, bares, restaurantes y otros lugares distantes de la casa, después cada quien regresaba para ahogar en la casa sus desafueros. Una vez que descomprimían la conciencia de tanto atisbo, quedaban en estado soñoliento frente a las pantallas mediáticas para caer anestesiados del sueño. A la mañana siguiente, la misma dinámica se repetía.

Pese a lo estancada que parezca esta vida, aún hoy ella fluye a través del tiempo como un río que no conserva la misma agua en su cauce. Desde antaño, el vivir humano ha sido eso: el resumen, en un espacio-tiempo preciso, de múltiples acciones que ocurren 
conjuntamente — dígase respirar, observar, digerir, caminar, habitar, etc.—, que se concatenan en el tiempo. El sentido ontológico del vivir ha estado en la dignificación que ofrece la muerte en un tiempo infinito inabarcable y la ocupación del espacio terrenal opuesto - no contrario- al divino.

En el tenor actual, vivir resulta indigno si la intranquilidad y la desesperación que condena al ser humano no le permite venerar al espacio y tiempo vividos. Como bien arguyó Byung-Chul Han, una vida así resulta desnuda, carente de continuidad y consistencia, correspondida sólo por la actividad laboriosa que transforma al mundo-de-la-especie-humana en la multitarea neurótica del consagramiento obligatorio y la pseudolibertad. ${ }^{14}$

Vivir ha sido el colofón del pensar y crear, del construir y transformar la realidad a gusto mientras existimos; ha sido la justificación del trabajo, de la realización y del habitar. No se vive si no se habita un espacio-tiempo preciso, limitado y finito por demás, reconocido y venerado. No se vive si no se mora una casa donde queden las aspiraciones y recuerdos del espíritu humano. En este sentido, el concepto casa remite al recinto de humanidad donde la seguridad dada por la razón se mezcla con el sentimiento dado por las pasiones, no es la máquina de habitar que indicó Le Corbusier. ${ }^{15}$

El hogar es el lugar común de humanidad donde la seguridad y el sentimiento son compartidos entre los seres humanos que lo ocupan. Por eso, el hogar fue simbolizado en la antigüedad a partir del fuego que mantiene cálidas a las personas reunidas en torno a él. Mantener el fuego encendido era, metafóricamente, conservar al hogar.

Nacemos y crecemos en una casa que aprehendemos como el hogar-mío inigualable y sempiterno. Relegamos entonces el concepto casa a todos los demás inmuebles en donde residimos a lo largo de la vida adulta. ${ }^{16}$ En aquel hogar queda la infancia ingenua y aprehensiva convertida luego en recuerdo, así como los sueños de aventura del adolescente impetuoso. Ese hogar representó el punto de partida hacia la exploración del mundo. Las demás casas que vamos habitando representan nodos de llegadas que estructuran la red de recuerdos e historias de vida. Estas moradas también son los puntos de retorno luego del avasallamiento del mundo externo.

\footnotetext{
${ }^{14}$ Byung-Chul Han, La sociedad del cansancio, trad. de Arantzazu Saratxaga (Barcelona: Herder, 2012), 29.

${ }^{15}$ Dania González, "La casa no es una máquina de habitar", Arquitectura y Urbanismo 28, núm. 1 (2007): 55-57. https://www.redalyc.org/pdf/3768/376839851009.pdf.

${ }^{16}$ Bachelard, La poética del espacio, 36.
} 
Bollnow expresó que siempre el ser humano regresará a esa morada que constituye el centro de su mundo vasto e inabarcable para su corto período de vida. ${ }^{17}$ Norberg-Schulz comprendió que en el hogar el espacio existencial toma el sentido íntimo que precisa, ${ }^{18}$ y Heidegger reafirmó que no hay individuo capaz de construir su vivienda sin, ontológicamente, haber habitado primero. ${ }^{19}$ Por su parte, Pallasmaa comprendió que la construcción del hogar es superior a la transformación material en casa, porque es una construcción del sentido y afecto transhumano. ${ }^{20}$

Más que un sitio de refugio donde el ser humano vulnerable a los peligros del mundo se resguarda para vivir en sosiego, el hogar se convierte en esa extensión de lo humano donde el individuo alcanza el recogimiento luego de enfrentar al desafiante mundo. En su seno, la realidad azarosa vuelve a ser amable en la cercanía del calor íntimo. El ser humano gana identidad en el arraigo que el vivir dentro le profesa; de no ser así, vagaría eternamente en la incertidumbre y el desamparo.

El problema que enfrentamos hoy es que la casa contemporánea refracta ese sentido del hogar fuera de la vida actual del ciudadano y lo instituye como un relato mítico. La chimenea que unía a los amantes en torno a su fuego, hoy es la calefacción que conforta al trabajador extenuado; la cocina cuya lumbre cooperaba en el arte culinario del individuo creativo ha sido sustituida por el rápido microondas. Ya no son acogidos todos los locales de la casa como cuando alguien leía tumbado en el sofá de la sala o buscaba respuestas a sus pensamientos en el cielo abierto del patio; hoy todo se reduce al dormitorio donde están la televisión, la computadora y el smartphone. Los ambientes domésticos de socialización han sido mudados hacia el espacio virtual de las redes sociales.

La casa ha perdido su representatividad como hogar único de afiliación e intimidad; hoy parece ser un recinto de ambivalencias dispares: sitio del reposo y del trabajo, el escenario de esporádicas convivencias sociales y el ámbito vacío de las reuniones virtuales, el depósito de los objetos testamentarios y el devorador de equipos automáticos

\footnotetext{
${ }^{17}$ Otto F. Bollnow, Hombre y espacio, trad. de Jaime López (Barcelona: Labor S. A., 1969).

18 Christian Norberg-Schulz, Existencia, espacio y arquitectura, trad. de Adrián Margarit (Barcelona: Blume, 1975).

${ }^{19}$ Martín Heidegger, “Construir, habitar y pensar”, en Yves Zimmerman (comp.), Conferencias y artículos (Barcelona: Ediciones Serbal, 1994).

${ }^{20}$ Juhani Pallasmaa, Habitar, trad. de Alex Giménez (Barcelona: Editorial Gustavo Gili, 2016), 16-30.
} 
obsolescentes y reemplazables. Empero, la casa sigue siendo el sitio del final del día, la última línea en la frenética cotidianidad, pero a la vez es el sitio despreciado cuando comienza la dinámica del tiempo aprovechable, ese tiempo de la eficiencia. Ella bien puede ser una morada y un reclusorio distante al sentido de hogar.

Cuando es una morada, su habitante no llega al recogimiento de paz y contemplación, sino que se sumerge en un estado frenético de gasto temporal con intenciones de esparcimiento donde la televisión, ${ }^{21}$ la navegación en Internet, ${ }^{22}$ las llamadas telefónicas y otras tantas nimiedades van gastando ese tiempo intermedio entre trabajo y trabajo. Por otro lado, cuando el habitante realiza un auto-reclutamiento disciplinario para estimular la tolerancia, la proactividad y el rendimiento que demandan la industria, las finanzas, la moda y los medios de comunicación, entonces la casa pasa a ser un reclusorio.

Tanto para quienes trabajan de ocho a doce horas diarias en oficinas o fábricas, como para quienes se recluyen en una habitación a remover laboriosamente los códigos informáticos de sus computadoras y smartphones, la casa queda cosificada como lo restante del sistema de espacios que cotidianamente visitan, usan y reconocen. El sistema externo de espacios que constituyen a la ciudad la reduce al mínimo. Como dijo la escritora Remedios Zafra: "la temporalidad y la contingencia de nuestros trabajos no propician comprometerse con las cosas, pero su ritmo mantiene la ilusión de que estamos activos". ${ }^{23}$ Incluso la Organización Internacional del Trabajo (OIT) reconoció el impacto en las vidas cotidianas y domésticas del trabajo virtual o hiperconectado para el cual la casa pasa a ser un espacio laboral más. ${ }^{24}$

Otro estudio global realizado por la OIT en el 2019 reveló la carga en intensidad laboral de los trabajadores. Así, los empleados temporales en Centroamérica tienen una

\footnotetext{
${ }^{21}$ Bureau of Labor Statistics, American Time Use Survey 2019 results (Washington, D.C.: Departament of Labor, 2020). https://www.bls.gov/news.release/pdf/atus.pdf.

${ }^{22}$ Pew Research Center, "Internet/Broadband fact sheet", Pew Research Center Internet \& Technology, 12 de junio, 2019. https://www.pewresearch.org/internet/fact-sheet/internet-broadband/.

${ }^{23}$ Remedios Zafra, "El malestar en la cultura: un texto de la ensayista Remedios Zafra", Arcadia, 29 de octubre, 2019. https://www.revistaarcadia.com/impresa/portada/articulo/el-malestar-en-la-cultura-un-textode-la-ensayista-remedios-zafra/78735/.

${ }^{24}$ Eurofound y OIT, Working Anytime, Anywhere: The Effects on the World of Work, (Luxembourg: Oficina de la Unión Europea/OIT, 2017), 3-60. https://www.ilo.org/wcmsp5/groups/public/---dgreports/---dcomm/--publ/documents/publication/wcms_544138.pdf.
} 
intensidad mayor que en otras regiones y más general que los trabajadores manuales y profesionales que responden principalmente a elevadas demandas cuantitativas y emocionales. Asimismo, en torno al tiempo laboral, son frecuente las largas jornadas de trabajo que incluyen días del fin de semana, e incluso los autoempleados trabajan horas demás. $^{25}$ Por ejemplo, profesionales, managers y ejecutivos estadounidenses pasan alrededor de 72 horas de los siete días semanales en actividades laborales. ${ }^{26}$

Fue en tenor crítico-reflexivo que Byung-Chul Han adujo que el individuo occidental admite su autoexplotación por un fin mayor a su individualidad benigna. La positividad de lo idéntico es ese fin. El sí-puedo-hacer es el dogma positivo que sumerge al individuo en la sobreabundancia, ahogándose en el cansancio y violentando su pacífica existencia. El ser humano, preso del agotamiento provocado por una egolatría proactiva hacia el éxito anticoligante de sí mismo, no rechaza, sino que admite a la superproducción, al sobrerrendimiento y a la supercomunicación que el mundo tiene en exceso para darle. Por eso, y para ello, trabaja arduamente hasta quedar extenuado de sí mismo y enfermo. ${ }^{27}$

Dicha extenuación se refleja en la casa del 'trabajador/a' donde, él o ella, se recluye no para protegerse de las amenazas externas, sino para, en cuerpo y espíritu, cebarse de externalidades dentro del espacio hermético y contenedor que su casa le brinda. Así, sale cebado de positividad, listo para más trabajo, más beneficios, más dinero, más consumo y más cansancio.

La casa es el ícono objetual del hartazgo del éxito desgastante. Ella absorbe el impacto del desgaste ocupacional, las depresiones y los diversos síndromes psicopatológicos del individuo, devolviéndole nuevos bríos. Funge como el lodazal anegado donde el habitante ahoga sus pulmones y se infla; el lodo son los sedimentos de penurias, decepciones e insatisfacciones mezclados con la abundante agua de la positividad, la efectividad y el rendimiento.

El individuo autoexplotado no encuentra reclamos en un otro que lo coarta y disciplina, pero si reclama en un algo que le ahogue; recurre al desahogo, para tomar

\footnotetext{
25 Ibid., 22-33.

${ }^{26}$ Jennifer J. Deal, Always on, Never Done? Don't Blame the Smartphone (San Diego: Center for Creative Leadership, 2015), 1. https://cclinnovation.org/wp-content/uploads/2020/02/alwayson.pdf.

${ }^{27}$ Han, La sociedad del cansancio, 45-51.
} 
fuerzas. Esta persona de hoy hace lo que puede hacer en lo inmediato, pensando en las posibilidades del mañana, en un presente prolongado siempre posible para él, así lo entendió Han. ${ }^{28}$ Para él todas esas posibilidades son planeables en la ergonómica casa que le brinda las condiciones para reforzarse en el emprendimiento de superar un día más. A consecuencia, la casa pasa a ser el lugar donde, por excelencia, cada persona asienta, a nivel manejable, analítico, solvente y reclamante, los problemas que le aquejan, a diferencia de la externa ciudad donde están todas esas posibilidades aguardándole.

La casa no es más el centro del mundo del ser humano, ahora lo es el trabajo, el espacio donde el homo laborans ejerce sus múltiples actividades laborales. ${ }^{29}$ En torno a éste, es articulada convenientemente la relación de lugares a usar diariamente: el mercado, el banco, el estacionamiento, etcétera. En esos lugares, ya sea en un parque, un templo o un bar, los problemas revolotean constantemente sobre la cabeza del ciudadano, picoteándole el sosiego. La ciudad es un constante sobresalto y preocupación, un insistente dudar y reprimir, un sistema instrumentado para incitar y regular.

La casa citadina es un instrumento más en esa regulación porque regula la negatividad de los desafueros del habitante y legitima la positividad. Ella es menos que la máquina lecorbusiana, pues representa una pieza de esa gran maquinaria que es la ciudad. La ciudad no empieza a partir de la puerta de la casa, sino desde las puertas mentales que dejan pasar a los imaginarios sociales.

Siguiendo a Han, esa máquina de rendimiento autista ${ }^{30}$ que es la sociedad, también es definida y definidora de la ciudad donde la casa continúa siendo un refugio, no de la carne ni de los temores, sino del cansancio por saturación. El refugio del cuerpo ahora es el Seguro de Vida, y el de los temores son los Reality Show. Y, pese a que aún está enquistado en el subsistir humano el temor a perder o nunca alcanzar el hogar, este parece haber desaparecido poco a poco.

\footnotetext{
${ }^{28}$ Ibidem.

${ }^{29}$ Montero, "Trabajador y espacio", 135-170.

${ }^{30}$ Han, La sociedad del cansancio, 36.
} 


\section{La casa objetual y sus sentidos metamórficos}

Para la ciudad instrumentada, la casa pasa a ser la necesaria residencia que asume al meroresidir-por-conveniencia. En ella, el individuo adulto mora temporalmente luego de terminar su jornada laboral para después abandonarla y volver al trabajo. También ignora su unidad doméstica mientras uno de sus locales baste para adentrarse en el espacio mediático y en el ciberespacio. Con esto, la casa parecer haber cambiado hacia un objeto que muta constantemente en varias formas figurativas y funcionales, cual una de ellas es ser el lodazal donde ahogar los desafueros.

Otra forma figurada y funcional de la casa citadina es ser un depósito de cosas temporalmente suficientes pero insuficientes. En ella quedan las regalías del exceso de trabajo y consumo que la decoran. Muebles, equipos eléctricos y ornamentados la van llenando. En ella prima la funcionalidad impía de albergar cosas; cosas que llegan y se van cuando se acaba su tiempo de presencia. La persona habitante también cumple con esta caracterización de cosa en su condición de arrendataria. Si llamáramos hogar a esta casa depósito, entonces cada objeto y mueble tendría un valor emocional incorporado, serían símbolo de una estirpe e historia y pasarían a la eternidad en torno al fuego hogareño que define a una familia y a una herencia. Si lo hiciéramos, ninguno de esos objetos comprados, rentados, adquiridos por diferentes vías, fueran desechables, sustituibles por otros más actuales y modernizados, más ineficientes en el tiempo y ajenos a la casa.

Si reconociéramos como hogar a este depósito rellenable tan sólo porque nos protege de la intemperie, entonces no habría diferencia entre una casa, una bodega y un almacén. En estos términos, la casa no sería un objeto emocionalmente diferenciable cual hogar, sino un receptáculo. Por otro lado, si reconocemos que en ella se lleva a cabo una forma particular de habitar basada en la utilidad de la descarga y recarga del ser humano en rendimiento, entonces ella sería un cubículo: un cubo de entropía cinética.

Un cubículo también es ese local reducido dentro de una oficina o despacho donde el flujo energético del trabajo va y viene, por lo que, en este sentido, la casa y la oficina guardan similitud. La única diferencia es que, en la primera, hay un carácter despojante ingénito, mientras que en la segunda el carácter es incorporativo exógeno. 
Ahora bien, todos estos sitios del hábitat mencionados tienen un valor de uso y otro de cambio asignados conforme a sus utilidades prácticas en el mercado. En el mundo capitalizado actual, la casa posee un valor de uso relativo de acuerdo con las necesidades, exigencias y estilos de vida de las personas, y tiene un valor de cambio fluctuante debido a sus cualidades rentables y vendibles. No obstante, hoy el ofrecimiento habitacional de la casa ha dejado a un lado el predominio del valor de uso para preponderar el valor de cambio. ${ }^{31}$ Los valores de ensueño e imaginación que Bachelard identificó dentro del valor de uso de la casa en tanto hogar ${ }^{32}$ han perdido su utilidad para el ser humano de hoy que cambia repetidamente de domicilio.

La casa citadina es ya un objeto de producción, rentabilidad y consumo, más que un refugio donde construir la vida afectiva y la herencia. ${ }^{33}$ Ella ha mutado en un sitio que acoge situaciones del ser humano autoexplotado, tal y como lo hacen muchos otros sitios en el entorno citadino. La casa no parece prevalecer entre este conglomerado de emplazamientos, por eso ha estado vulnerable al cambio de sentido.

\section{La casa como objeto impermanente}

El afán del ciudadano contemporáneo de moverse en lo idéntico y de alcanzar el éxito individual queda expresado en las características físicas, ambientales y decorativas de la casa. Comúnmente ellas son diseñadas y construidas en masa bajo criterios homogéneos. Las inmobiliarias y desarrolladoras habitacionales se ciñen a la repetición masiva de una forma residencial de bajo costo donde habitarán la clase media y baja. ${ }^{34}$ Y similarmente, las viviendas de clase media alta recrean códigos formales y espaciales comunes entre sí como exageración obligada para trasmitir a sus iguales la grandilocuencia del estatus económico y social de la familia.

\footnotetext{
${ }^{31}$ David Harvey, Diecisiete contradicciones y el fin del capitalismo, trad. de Juan Mari Madariaga (Quito: Editorial IAEN, 2014), 31-40.

${ }^{32}$ Bachelard, La poética del espacio, 36.

${ }^{33}$ Harvey, Diecisiete contradicciones, 31.

34 Sergio Gallardo, "La vivienda social: el eterno problema", Portavoz, 21 de enero, 2016, http://portavoz.tv/la-vivienda-social-el-eterno-problema/.
} 
Normalmente, las familias obreras pasan poco tiempo en esas casas clonadas porque trabajan la mayor parte del día. Las familias pudientes apenas usan toda la vivienda como un sistema de espacios afectivos. Tanto una casa como la otra son vendidas o rentadas repetidamente a nuevos propietarios o inquilinos quienes rentan o venden por igual. Al final, todas estas personas son pasantes en sus casas, incitadas por la unificación de las ofertas en el mundo. La flexibilidad y globalización laboral, la libertad empresarial trasnacional o la búsqueda de diferentes condiciones de vida que ofrece el mundo abierto son factores de esta pasantía.

La casa se instaura entonces como un producto rentable de consumo temporal, estrechamente vinculada a la movilidad, al tránsito y a los sistemas de transportación. Al acortarse las distancias por medio del automóvil, el tren bala y el avión, la casa puede ser reemplazada por otra en cualquier parte del mundo; supone un objeto que utilizamos aquí y ahora y que es utilizable en otro lugar geográfico a través de su mera funcionalidad. Queda en crisis el apego emocional o la empatía a una casa vivida, pues basta con tener a disposición la materialización que ella representa. Mientras el hogar no puede ser reducido a un producto de consumo desechable, la casa sí, a la vez que es admitida en la misma liquidez en que fluye la conveniencia laboral y el mar de demandas a nivel mundial. ${ }^{35}$

El disponer de una casa, de un empleo que tribute elevados ingresos, de la tecnología, del reconocimiento social y de la positividad del mundo actual son ingredientes cruciales en el éxito del ser humano contemporáneo. Todas estas son posibilidades y oportunidades que la ciudad ofrece para vivirla. No es de extrañar que sean las personas de la generación millennial quienes prefieren rentar una casa antes que comprarla, pues su objetivo es explotar todas las posibilidades del mundo globalizado e hiperconectado. ${ }^{36}$ Esta generación joven tiene mayor apego a la positividad de lo idéntico que a la casa como hogar. Un hogar alude a la identificación propia y diferenciadora con respecto a los demás, algo que contradice la cuestión positiva actual de sobresalir sin negar al otro. El éxito

\footnotetext{
${ }^{35}$ Zygmunt Bauman, Modernidad líquida, trad. de Mirta Rosenberg y Jaime Arrambide (México: Fondo de Cultura Económica, 2003), 59-178.

${ }^{36}$ Redacción de Excelsior, "Millennials prefieren rentar que comprar una vivienda", Excelsior, 26 de junio, 2018. https://www.excelsior.com.mx/nacional/millennials-prefieren-rentar-que-comprar-una-vivienda/1248145\#view-1.
} 
entonces está en la superpositividad del individuo sobreexplotado por sí mismo dentro de la equitativa nulidad de lo positivo. ${ }^{37}$

En estas circunstancias, el éxito queda subvalorado, condenado a una celda dictada por el criterio social. Es algo heredado, pues siempre el éxito ha sido reconocido a partir de las acciones humanas con resultados positivos en contraposición a la posibilidad de resultados negativos o fracasos. Mas, en la actualidad, el éxito refiere al logro positivo a nivel social, pero negativo en lo individual porque entraña autoviolencia. Ya no es el logro excelso entre tantos otros logros usuales; ahora está convenientemente asociado con la eficacia y el rendimiento: éxito en el trabajo, en los negocios, en las finanzas, en la familia y en la sociedad.

La familia es instaurada entonces como un éxito ante la sociedad. ${ }^{38}$ Actualmente, su estructura ha variado mucho según las permisibilidades legales de los países; sin embargo, la familia continúa siendo admitida como la realización biológica y moral del ser humano, pues en ella está la descendencia y la unión marital de los individuos. ${ }^{39}$ Constituye el logro de la convivencia grupal en la seguridad de la vivienda, la primera unión social del ser humano. Por ello, la persona es considerada exitosa cuando alcanza la estabilidad económica y sentimental en su vida, así como en las vidas de quienes le acompañan en la casa. Así, la familia y la casa se trenzan en la empresa de construir un hogar. ${ }^{40}$

\section{La casa sin potencial interpersonal}

Construir un hogar precisa, entre varios factores, del recogimiento puro en la casa; ése que, como fue enunciado en párrafos anteriores, lleva a la contemplación y a la paz. El hogar debe remitir al recogimiento del individuo y de la familia, ambos como representación del Uno que

\footnotetext{
${ }^{37}$ Han, La sociedad del cansancio, 45-51.

${ }^{38}$ Friedrich Engels, El origen de la familia, de la propiedad privada y del Estado (Madrid: Akal, 2017), 7296; Alfonso Mata, "Sobre los millenials, los baby boomers", Diario La Hora, 18 de agosto, 2017, https://lahora.gt/los-millennials-los-baby-boomers/; Ana Martha González, "Introducción”, en Ana Martha González, Pilar Arregui y Carolina Montoro (eds.), Familia y sociedad en el siglo XXI (Madrid: Dykinson, 2016), 12.

${ }^{39}$ Ibid., 10-12.

${ }^{40}$ Raffaella Sarti, Casa e família. Habitar, comer e vestir na Europa Moderna, trad. de Isabel Teresa Santos, (Lisboa: Estampa, 2001), 75-76.
} 
trasciende del Yo al Nosotros y viceversa. Al construir un hogar se posee aquello fundamental que el ser humano lega a su descendencia; es el ambiente apropiado para instruir a los hijos, traspasar valores y normas, para trasmitir una memoria del vivir y una herencia cultural. ${ }^{41}$ Tal construcción inicia con el ideal de hogar mientras residimos en las diferentes casas a lo largo del tiempo. Y este ideal que tiene sus cimientos en aquel hogar vivido en la infancia pasa a ser un proyecto planificable hacia el acondicionamiento de la casa burda como hogar de la futura familia. El recogimiento puro toma relevancia entonces en el espíritu afanoso del habitante, porque reaparece como un anhelo posible y laborioso donde el individuo se identifica como ser de memoria y ética para fundar una familia y legar. Allí comienza a condensarse ese hogar idealizado que luego se solidifica en la casa material.

Antes de que eso pase, toda casa citadina ocupada a lo largo del tiempo ha refractado el sentido de hogar fuera del presente hacia un pasado y un futuro: primero, hacia el hogar-mío de la infancia y, luego, hacia el hogar-suyo de la familia. Ese hogar-mío reconocido y memorizado pasará a ser el hogar-suyo donde la venidera generación crecerá en el núcleo familiar. Hasta entonces, el individuo autoexplotado vaga de casa en casa sin enraizarse en ellas, profundiza sus raíces en el trabajo y el éxito profesional, y se afianza al rendimiento y a la eficiencia. Su objetivo es llegar a lo más alto, no permanecer fiel a un suelo preciso.

\section{La casa y el ser trascendente del hogar}

A pesar de que el hogar ha sido desvanecido en mera casa donde ahogar los desafueros intensificados en la vida diaria, y hoy, en tiempos de confinamiento domiciliar, la casa se vuelve extraña e intolerable, tengo confianza en que el hogar resurge. Si bien, la casa citadina actual es símbolo de una vida sin significado trascendente, de una vida con significados efímeros y consumibles en la inmediatez, el hogar vuelve a la vida humana como redención del significado de lo humano.

La casa citadina actual es ejemplo de la dinamización frenética del vivir fugaz, del sobrevivir al evento inmediato a favor del evento siguiente, del más en menos tiempo, del

\footnotetext{
${ }^{41}$ Ibidem; Pallasmaa, Habitar, 18-23.
} 
gasto humano que el individuo y la sociedad desprenden cada día, del esfuerzo, la supereficacia, la sobreexplotación de los activos físicos, mentales y sentimentales, y de la pérdida. Ella es el susurro constante de que ya no somos hogareños, pues hemos canjeado ese sentimiento por el sobrerrendimiento y el superconsumo. El ser humano adulto pierde, en ese período de vida, la empatía hacia el hogar, suplantándola por la factibilidad de la casa impropia y rentable. A consecuencia deja de ser hogareño, deja de identificarse con aquello más próximo a su cuerpo y, en el proceso, se identifica con los cuerpos-otros abundantes en la ciudad, con los múltiples lugares foráneos.

La redención está en el pasado y el futuro, en ese hogar-mío que marcó la infancia y puso la pauta del hogar genérico. Las condiciones de habitabilidad, el confort de sus ambientes, la amabilidad de sus espacios y la carga emotiva en cada uno de sus locales cualifican al hogar vivido en la niñez y fungen como factores reproducibles en el hogar a construir para las venideras generaciones. Por tanto, a consideración resuelvo que el hogar es, tanto aquel de tiempos pueriles, como ese de la vejez.

En mi opinión, el hogar del entretiempo es un polvo difunto suspendido sobre las múltiples casas resididas; es irrecolectable e inmezclable con el lodazal de la anegación doméstica en que está sumergida la adulta persona citadina y laboralmente comprometida. Como una utopía, el hogar del pasado que inconsistente permanece flotando en la memoria, resurgirá en un futuro de cansancio cuando las personas recuperen la calma del reposo y el legado. Hasta ese momento, el hogar permanecerá disipado, difuso y misterioso para una fase de vida humana que sólo puede idealizarlo.

Es en ese ocaso de la vida cansada que el hogar resurge para honrar la memoria e instaurarse como el hogar-mío recordado que pasa a ser el hogar-suyo del legado mnemónico. Ésta es la importancia esencial del hogar: ser referencia mnemónica del ser humano. Por ello, cuando el hogar no está presente, la memoria queda débil, incompleta, imprecisa y vulnerable.

La casa citadina no funda memoria, más bien la disipa en un ambiente fugaz. El habitante en ella no recuerda cómo es habitar en fidelidad y pureza y por ello se doblega a las formas alternas de habitar que la modernidad o postmodernidad impone. El individuo citadino habita-sin-Habitar la urbe, el ciberespacio, la bolsa de valores, la moda, la economía neoliberal, la igualitariedad, y la positividad de ser y hacer. Metafóricamente 
prefiero comprender a esta persona (in)habitante, como un reptil anfibio que muda gradualmente la piel para ajustarse a los convencionalismos de la realidad ciudadana. Como un fantasma, tiene su sentimiento anclado al viejo hogar de la infancia y, como espectro reencarnado, va a construir uno nuevo para su descendencia. Con cada cambio de casa el espíritu de Habitar cambia, por eso, propugno que todo ser humano contemporáneo es domomorfo.

Como proverbio universal, se reconoce y difunde que la ciudad es la gran casa del ser humano sin pensarla como hogar, y ahí está el engaño. Me consta, por experiencia, que las personas de campo poseen una casa que constituye un hogar invariable e imborrable; un hogar que acoge alrededor de su fuego familiar a los objetos tecnológicos contemporáneos y no pierde su significado como símbolo de la identidad cultural de la familia y de la comunidad. Ella es baluarte mnemónico de estirpe y herencia. Entonces, ¿por qué en la ciudad el hogar ha perdido su sentido trascendental, dejando desprovista a la casa de él y convirtiéndola en su antípoda? ¿Es el uso de la casa lo que define al hogar o es su sentido trascendente? ¿Somos nosotros culpables de ello por designar tal uso conforme a su explotación? Con esto vale la pena reflexionar sobre la situación anti-hogareña evidenciada hoy en tiempos de pandemia y confinamiento doméstico.

\section{Conclusión para reflexionar}

Las respuestas a estas preguntas llegan gota a gota y luego en cascada a partir de lo antes dicho. Primero hay que decir que, bajo cualquier régimen de explotación, las cosas pierden importancia y sentido, incluso la vida cae en tales términos. Con la autoexplotación del individuo llega su autoviolencia que distorsiona la empatía hacia la realidad y, a consecuencia, las realidades sentimentales se vuelven irrealidades despreciables. La casa citadina cae dentro de tales irrealidades y con ella el hogar se pierde en ese abismo oscuro. Sin embargo, hay una esperanza, una luz en la cima: el hogar vuelve a iluminar tras el cansancio de tanto exceso, siendo el horizonte de la tranquilidad y el ocaso. Es en el construido hogar-suyo que el cansancio supera a la extenuación y pasa a ser reparación finita, contemplación sosegada, recuerdo nostálgico y confianza pacífica. Este cansancio 
abre al ser humano para que, su sentido-de-ser y el de otros, le llene. El fin de la vida va llegando y el hogar es el mejor lugar para recibirlo.

Saber que la vida fluye por los actos humanos y se solidifica en cada objeto invaluable que acogemos en coexistencia, es el principio de un vivir pleno, digno y trascendente. Esa solidificación de la vida deviene en memoria que las venideras generaciones recordarán y harán suya. La casa actual no es igual a la de antaño, pero el sentido de hogar perdura a través de los años. Este es el sentido inmanente al vivir en absoluto cohabitar con el mundo, y es el sentido trascendente en significado. El significado de hogar perdura, aunque el objeto que lo represente mute. El hogar no se ha perdido, ha sido ocultado durante un período de la vida humana.

Hoy las personas adultas en confinamiento domiciliar padecen los síntomas de ese ocultamiento y no soportan permanecer tanto tiempo dentro de las casas cuando ya se les han agotado las opciones para consumir el tiempo, cuando ya no hay programa televisivo que enajene ni Internet que absorba. En estas circunstancias, la mera casa objetual es un total reclusorio inabandonable y sus estragos en las emociones y psiquis se hacen palpables. La vulnerabilización doméstica a la que se ha sometido el ser humano autoexplotado queda en evidencia.

Basta puntualizar que todo ello es un efecto secundario de la droga que el capitalismo nos ha suministrado. La acción de vivir resulta conveniente para los intereses económicos, pero el ser hogareño es un obstáculo. La persona que ama a su hogar no sede ante la globalización ni la competitividad neoliberal, se apega a lo propio reconocido sin importar los descalabros del mundo ignoto y fágico; preferiría sobrevivir en el calor de su hogar, que perecer devorado por los designios, convencionalismos e imperativos externos. La casa impropia es un dispositivo del sometimiento, y el sentido de hogar es momentáneamente desvanecido entre la rabia de eficiencia, los desenfrenos de individualismo y supremacía, la vehemencia del rendimiento y la idoneidad, las ansias de éxito y la autoexplotación positivista.

El exceso de positividad interfiere en la perdurabilidad del hogar, porque el habitante de ciudad asiente a las prerrogativas del paradigma antrópico del Hombre Prometeico que, como bien refirió Han, ${ }^{42}$ se sacrifica para ser reconocido en el éxito. Éste

\footnotetext{
${ }^{42}$ Han, La sociedad del cansancio, 6.
} 
es el acto que le lleva al encadenamiento en la montaña que no puede romper. Ergo, la Tierra de los seres humanos se vuelve su hogar.

El hogar siempre será la cadena benigna que nos define como seres humanos a diferencia de las máquinas y las deidades; que nos da fortalezas más que vulnerabilidades. Conservar su esencia humana sirve de fuerza y consuelo ante las dificultades y calamidades. Pero, cuando es un lodazal donde ahogar los desafueros, pierde esa esencia protectora. Es necesario entonces rescatarlo como pradera donde sembrar sentimientos y ser resilientes en contra de nuestras vulnerabilizaciones cotidianas. 


\section{Bibliografía}

Associated Press. "Cuando quédate en casa suena a prisión domiciliaria”. 20 minutos, 6 de marzo, 2020. https://www.20minutos.com/noticia/273972/0/cuando-quedate-encasa-suena-a-prision-domiciliaria/.

Bachelard, Gastón. La poética del espacio, trad. de Ernestina de Champourcin. Buenos Aires: Fondo de Cultura Económica, 2000.

Bauman, Zygmunt. Modernidad líquida, trad. por Mirta Rosenberg y Jaime Arrambide. México: Fondo de Cultura Económica, 2003.

Bloom, Nicholas. "How working from home works out". Stanford Institute for Economic Policy Research, junio, 2020. https://siepr.stanford.edu/research/publications/howworking-home-works-out\#anchor-1.

Bollnow, Otto F. Hombre y espacio, trad. de Jaime López. Barcelona: Labor S. A., 1969.

Brooks, Samantha K., Rebecca K. Webster, Louise E. Smith, Lisa Woodland, Simon Wessely, Neil Greenberg y Gideon J. Rubin. "The Psychological Impact of Quarantine and How to Reduce it: Rapid Review of the Evidence", The Lancet, 395, núm. 10227 (marzo, 2020): 912-920. https://doi.org/10.1016/S01406736(20)30460-8.

Bureau of Labor Statistics. American Time Use Survey 2019 results. Washington D.C.: Departament of Labor, 2020. https://www.bls.gov/news.release/pdf/atus.pdf.

Castillo, Juan José. "La soledad del trabajador globalizado". Revista Papeles, núm. 108 (invierno, 2009): 11-20. https://www.fuhem.es/wp-content/uploads/2018/12/la_soledad _del_trabajador_globalizado_J.J.CASTILLO.pdf.

De la Garza, Enrique (Coord.). Trabajo no clásico, organización y acción colectiva. México: Universidad Autónoma Metropolitana / Plaza y Valdés, 2011.

De Vita, Verónica. "El teletrabajo ha generado más estrés y también ha obligado a ampliar el horario laboral". Los Andes, 19 de abril, 2020. https://www.losandes.com.ar/article/view/?slug=el-teletrabajo-ha-generado-masestres-y-tambien-ha-obligado-a-ampliar-el-horario-laboral. 
Deal, Jennifer J. Always on, Never Done? Don't Blame the Smartphone. San Diego: Center for Creative Leadership, 2015. https://cclinnovation.org/wpcontent/uploads/2020/02/alwayson.pdf.

Engels, Friedrich. El origen de la familia, de la propiedad privada y del Estado. Madrid: Akal, 2017.

Eurofound y OIT. Working Anytime, Anywhere: The Effects on the World of Work. Luxembourg: Oficina de la Unión Europea / OIT, 2017. https:/www.ilo.org/wcmsp5/groups/public/--dgreports/---dcomm/---publ/documents/publication/wcms_544138.pdf.

Eurofound y OIT. Working Conditions in a Global Perspective. Luxembourg: Oficina de la Unión Europea / OIT, 2019. https://www.ilo.org/wcmsp5/groups/public/--dgreports/---dcomm/---publ/documents/publication/wcms_696174.pdf.

Gallardo, Sergio. "La vivienda social: el eterno problema”. Portavoz, 21 de enero, 2016, http://portavoz.tv/la-vivienda-social-el-eterno-problema/.

Gallo, Catalina. "Estudios muestran que la pandemia y el confinamiento han afectado la salud mental de la población”. France 24, 11 de septiembre, 2020. https://www.france24.com/es/20200911-impacto-pandemia-salud-mental.

Guerra, Pablo. Sociología del trabajo. Montevideo: Kolping, 2011.

González, Ana Martha. “Introducción”. En Ana Martha González, Pilar Arregui y Carolina Montoro (Eds.), Familia y sociedad en el siglo XXI. Madrid: Dykinson, 2016.

González, Dania. “La casa no es una máquina de habitar”. Arquitectura y Urbanismo 28, núm. 1 (2007): 55-57. https://www.redalyc.org/pdf/3768/376839851009.pdf.

Han, Byung-Chul. La sociedad del cansancio, trad. de Arantzazu Saratxaga. Barcelona: Herder, 2012.

Harvey, David. Diecisiete contradicciones y el fin del capitalismo, trad. de Juan Mari Madariaga. Quito: Editorial IAEN, 2014.

Heidegger, Martín. "Construir, habitar y pensar". En Yves Zimmerman (Comp.), Conferencias y artículos. Barcelona: Ediciones Serbal, 1994.

Mata, Alfonso. "Sobre los millenials, los baby boomers". Diario La Hora, 18 de agosto, 2017. https://lahora.gt/los-millennials-los-baby-boomers/. 
Montero, Jorge Luis. "Trabajador y espacio del trabajo contemporáneo. Crítica ontológica al empleo". Sincronía, núm. 78 (julio-diciembre, 2020): 135-170. doi:10.32870/sincronia.axxiv.n78.7b20.

Norberg-Schulz, Christian. Existencia, espacio y arquitectura, trad. de Adrián Margarit. Barcelona: Blume, 1975.

Pallasmaa, Juhani. Habitar, trad. de Alex Giménez. Barcelona: Editorial Gustavo Gili, 2016.

Pew Research Center. "Internet/Broadband fact sheet". Pew Research Center Internet \& Technology, 12 de junio, 2019. https://www.pewresearch.org/internet/factsheet/internet-broadband/.

Redacción de Excelsior. "Millennials prefieren rentar que comprar una vivienda", Excelsior, 26 de junio, 2018. https://www.excelsior.com.mx/nacional/millennialsprefieren-rentar-que-comprar-una-vivienda/1248145\#view-1.

Sarti, Raffaella. Casa e família. Habitar, comer e vestir na Europa Moderna, trad. de Isabel Teresa Santos. Lisboa: Estampa, 2001.

Valenzuela, María E., y Claudia Mora (Eds.). Trabajo doméstico: un largo camino hacia el trabajo decente. Santiago de Chile: Organización Internacional del Trabajo, 2009.

Weber, Max. La ética protestante y el espíritu del capitalismo, trad. de Luis Legaz. México: Fondo de Cultura Económica, 2012.

Zafra, Remedios. "El malestar en la cultura: un texto de la ensayista Remedios Zafra". $\begin{array}{llll}\text { Arcadia, } & 29 & \text { de } & \text { octubre, }\end{array}$ https://www.revistaarcadia.com/impresa/portada/articulo/el-malestar-en-la-culturaun-texto-de-la-ensayista-remedios-zafra/78735/. 